\title{
Title: Intranasal oxytocin drives coordinated social approach
}

Patrick K. Monari ${ }^{1 \dagger}$, Nathaniel S. Rieger ${ }^{1,2}$, Juliette Schefelker ${ }^{1}$, Catherine A. Marler ${ }^{1}$

${ }^{1}$ Department of Psychology, University of Wisconsin-Madison, Madison, WI, USA

${ }^{2}$ Department of Psychology and Neuroscience, Boston College, Chestnut Hill, MA, USA

${ }^{\dagger}$ Correspondence to: Patrick Monari, monari@wisc.edu 


\begin{abstract}
Coordinated responses to challenge are essential to survival for bonded monogamous animals and may depend on behavioral compatibility. Oxytocin (OT) context-dependently regulates social affiliation and vocal communication, but its role in pair members' decision to jointly respond to challenge is unclear. To test for OT effects, California mouse females received an intranasal dose of OT (IN-OT) or saline after bonding with males either matched or in their approach response to an aggressive vocal challenge. Pair mates were re-tested jointly for approach response, time spent together, and vocalizations. Females and males converged in their approach after pairing, but mismatched pairs with females given a single dose of IN-OT displayed a greater convergence that resulted from behavioral changes by both pair members. Unpaired females given IN-OT did not change their approach, indicating a social partner was necessary for effects to emerge. Moreover, IN-OT increased time spent approaching together, suggesting behavioral coordination beyond a further increase in bonding. This OT-induced increase in joint approach was associated with a decrease in the proportion of sustained vocalizations, a type of vocalization that can be associated with intra-pair conflict. Our results expand OT's effects on behavioral coordination and underscore the importance of emergent social context.
\end{abstract}

Keywords: Oxytocin; intranasal oxytocin; pair bonding; coordination; approach; ultrasonic vocalizations; Peromyscus californicus; California mouse 


\section{Introduction}

Coordinated behavior is essential to compatibility and survival for species that are biparental and develop mating pair bonds. Examples across vertebrate taxa illustrate environmental and social challenges that require joint strategies by bonded partners [1-3], and for monogamous and territorial species one such challenge is the introduction of an unfamiliar conspecific. Pairs with an established bond must appropriately recognize and confront outgroup individuals, as their presence threatens territorial infringement [4], resource theft [5], and infanticide [6], all of which can hamper pair fitness [7-9]. Some species, such as cichlid fish [10] and Kirk's dik-dik [11] respond with rigid, sex-specific behavioral roles such that one sex invariably defends territories while the other cares for offspring. Other pair bond-forming species, however, display more flexible behavior between sexes. For example, prairie vole $[12,13]$ and California mouse [14-16] pair mates closely overlap in their behavior, and both sexes can complete any necessary task besides nursing. Compatible responses between pair-bonded individuals to an extrapair challenge are therefore uniquely important to coordination in these species.

The neuropeptide oxytocin (OT) context-dependently regulates social affiliation [17] and vocal communication [18], and by extension may impact response compatibility, but its role in pair members' decision to jointly react to challenge is unclear. OT signaling facilitates prosocial behaviors in some cases, while it promotes social vigilance [19], social anxiety [20], and agonistic behaviors $[21,22]$ in others. The effects of OT on investigation and aggression are therefore complex and rely on social context [23] and may modulate behavior and emotion by enhancing an individual's attunement to its social landscape [24-26]. For example, in marmosets, intranasal OT (IN-OT) increased approach towards an unfamiliar conspecific when a mate was also present but decreased approach when the mate was absent [27]. In humans, IN-OT reduced xenophobic 
aggression when paired with injunctive prosocial norms of peers, but not when administered without them [28]. Taken together, this evidence supports the notion that OT signaling influences how social affiliations moderate responses to the outgroup. response to intrusion, with varying degrees of individual and joint approach by pair members, suggesting variability in pair coordination and division of labor [37]. Flexible application of coordinated strategies may depend on the type and degree of challenge; in some cases, joint action may help to efficiently remove a threat, while in other cases it might be advantageous to divide location and simultaneously defend resources or pups while addressing an intruder. We recently found that, prior to pup birth and following pair-bonding, individuals of both sexes adjusted to match their partner's level of approach in a compatibility-dependent manner when

42 exposed to a low level of challenge; paired individuals that were mismatched (one individual

43 higher, one lower) in their approach before pairing were more likely to change their behavior to

44 become similar after pairing, while matched pairs (similar levels of approach between

45 individuals) changed little. The change in behavior for mismatched pairs was associated with 
47 vocal communication plays a role in the decision to adopt one coordination type over the other, as paired California mice display a rich variety of USVs that have been linked to complex social

49 behavior $[39,40]$. However, the neuroendocrine mechanisms underlying this coordination-

50 induced change to social approach have yet to be studied.

OT can context-dependently regulate approach and avoidance of a novel conspecific in

52 female California mice [41,42]. Here we used female IN-OT administration and pre-pairing/post-

53 pairing simulated intrusions, via playbacks of aggressive vocalizations, to show that OT is critical

54 to mediating pair-bonding-induced changes to social approach. Two hypotheses emerge for how

55 OT may modulate pair coordination in response to challenge: the convergence hypothesis predicts

56 that OT will increase the similarity between pairs mismatched in their degree of social approach,

57 increasing the amount of time pair mates spend jointly addressing an unfamiliar intruder $[43,44]$.

58 Conversely, the divergence hypothesis predicts that OT can increase the dissimilarity between

59 matched pairs, increasing the amount of time pair mates spend apart, thereby dividing labor [37].

60

61

62

63

64

65

66

67

68

69

70

71 


\section{Methods}

73 Animals

48 adult males and 48 adult females (age 3-6 months) were housed in standard cages (48 x

$7527 \times 16 \mathrm{~cm}$ ) lined with aspen bedding and a nestlet with Purina $5015^{\mathrm{TM}}$ mouse chow and water

76 available ad libitum, 2-4 same-sex individuals per cage. All tests occurred between 1-3 hrs after

77 the onset of the dark cycle in dim red light in housing maintained at $20-23^{\circ} \mathrm{C}$ on a $14: 10 \mathrm{~h}$

78 light:dark cycle (lights on at 16:00 central standard time). Males and females were tested for

79 response to bark playbacks and were selectively paired and housed in new cages. In a separate

80 experiment, 20 females were left unpaired and housed with their original cage mates.

\section{Ethical statement}

Animals were maintained according to the National Institute of Health Guide for the Care

83 and Use of Laboratory Animals. Procedures were approved by the University of Wisconsin-

84 Madison College of Letters and Sciences Institutional Animal Care and Use Committee (Protocol

85 L005447). No animals were injured by any of the behavioral manipulations or assays.

\section{Apparatus}

87 Testing occurred in aspen bedding-lined Plexiglas cages $(90 \times 30 \times 30 \mathrm{~cm})$ equally divided

88 into three chambers (each $30 \times 30 \times 30 \mathrm{~cm})$ with centrally located openings $(11.5 \times 11.5 \mathrm{~cm})$

89 between chambers to allow for free movement. Speakers (Vifa Dynamic Ultrasound, 1-120 kHz

90 range, Avisoft Bioacoustics, Berlin, Germany) were placed at each end of the apparatus against a

91 closed mesh gate.

$92 \quad$ Playback tracks 
We investigated California mouse approach behavior towards playbacks of loud, aversive

94 bark calls, adapted from [38, in review]. In a separate cohort used exclusively to produce the playback stimuli, individual male and female mice were placed in a single-chambered plexiglass apparatus $(50 \times 30 \times 30)$ under normal food and water conditions for 24 hrs, a length of time demonstrated to be sufficient for the formation of residency behavior, and in which the arena becomes the individual's territory [36]. After $24 \mathrm{hrs}$, residents were introduced to a same-sex intruder for an 8-min aggressive encounter period similar to previous studies $[32,33,36,45,46]$. Each intruder was only used for a single encounter, and otherwise had no previous aggression testing experience. During the encounter we recorded defensive-aggressive barks using an ultrasonic microphone (Emkay/Knowles FG series, detection range: 10-120 kHz) with a $250 \mathrm{kHz}$ sampling rate and 16-bit resolution, placed $30 \mathrm{~cm}$ above the bottom of the apparatus. Spectrograms were produced using a 512 fast Fourier transform in Avisoft SASlab pro (Avisoft Bioacoustics, Berlin, Germany) in order to identify barks. Barks appear as short, high-amplitude calls with an upside down $U$ shape that begins and ends in the audible range for humans [16,47] (Fig. 1A). We created playback tracks using these spectrograms by selecting only bark calls. Calls could not be distinguished between the resident and the intruder during the encounter, therefore both resident and intruder barks were used to construct playback tracks. Playback tracks were 2 mins in duration and contained $120 \pm 5$ bark calls. Output gain/volume was maintained across playback tracks. The ambient noise track control was a 2 min recording of the quiet testing room with all lights off and no mice present. We used 8 unique tracks from 8 different sets of individuals and assigned tracks to individuals randomly with each track used between 20-23 times [38, in review], ensuring that no individual heard the same track more than once over the course of the two tests (to avoid habituation and maintain consistency). 
bioRxiv preprint doi: https://doi.org/10.1101/2020.11.20.390245; this version posted June 17, 2021. The copyright holder for this preprint (which was not certified by peer review) is the author/funder, who has granted bioRxiv a license to display the preprint in perpetuity. It is made available under aCC-BY 4.0 International license.
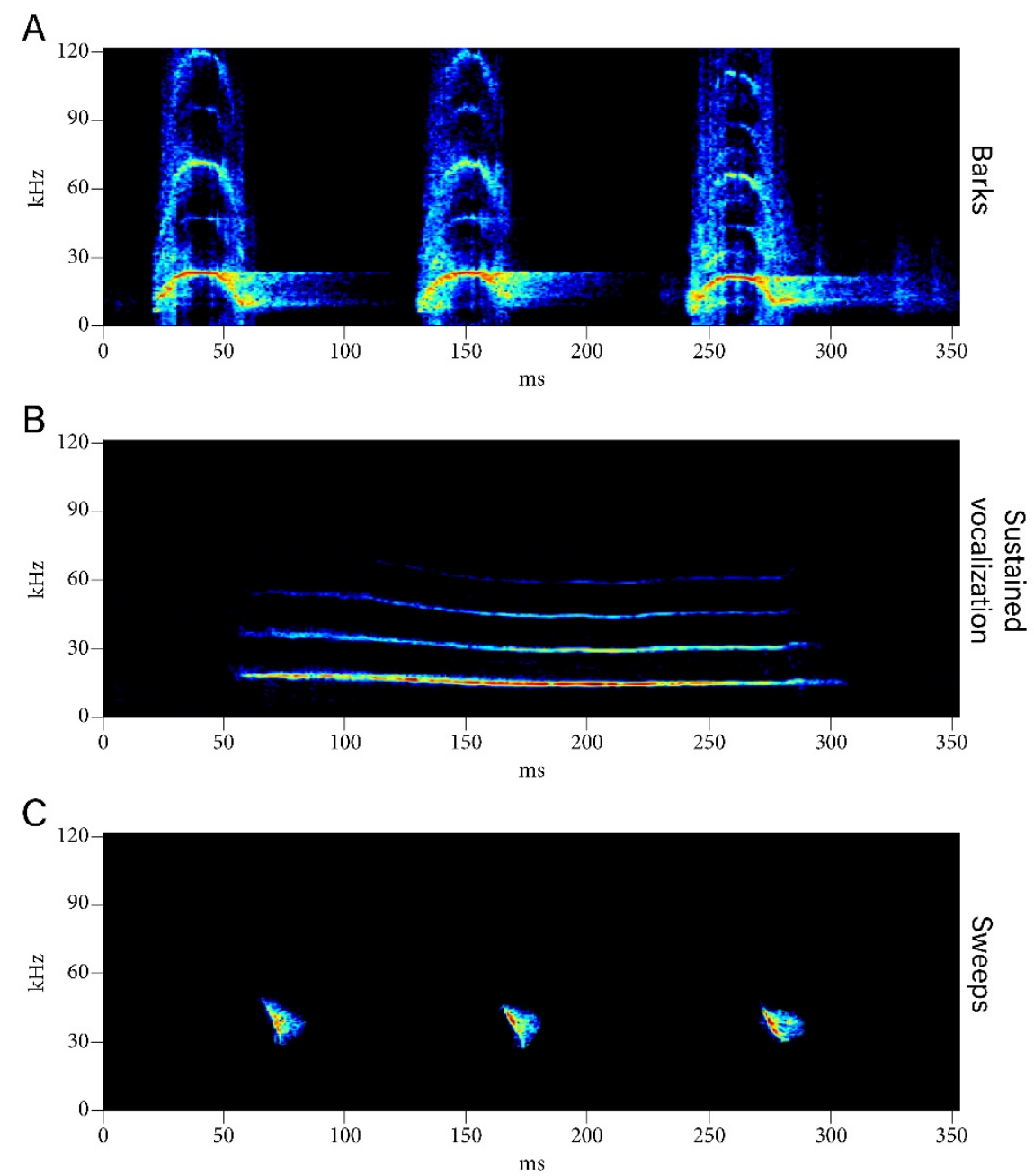

117 Figure 1. California mouse vocalizations. Examples of A. Barks, B. A sustained vocalization (SV),

118 and C. Sweeps. 
125

126

127

128

129

Pre-pairing playback approach test

Mice were first tested for response to bark playbacks as nonbonded, sexually naïve individuals (Fig. 2A, left). Mice were placed in the testing apparatus for 5-10 mins to habituate to all three chambers. One male and two females did not enter all three chambers by 10 -min and so were removed from the experiment (resulting in 47 males and 46 females). Two-min playback tracks were played from speakers at opposite ends of the apparatus behind wire mesh, with one speaker playing a bark track and the other an ambient noise track concurrently. The bark track and ambient noise track speaker locations were randomized across trials. Video and audio recordings were made of their behavior. We recorded time spent in the chamber closest to the bark speaker (“approach chamber") as an approach score, and aggregate time spent in the chamber closest to the ambient noise speaker ("avoid chamber") as an avoidance score.

\section{Behavioral type and pairing}

3-7 days following the pre-pairing test, 46 females were selectively paired with 46 males in a stratified randomized design based on approach scores. Mice were paired such that they were "matched" in their approach scores (i.e., their approach scores were $\leq 10 \mathrm{~s}$ different from each other, $\mathrm{N}=17$ ) or they were "mismatched" (i.e., their approach scores were $\geq 30 \mathrm{~s}$ different from each other, $\mathrm{N}=29$ ). There were no pairs formed that had an approach score difference between 10 and $30 \mathrm{~s}$. In a follow-up experiment, 20 female mice were left unpaired following the first playback approach test.

\section{Post-pairing playback approach test}

All mice underwent a second playback test to determine if pairing alters responses to bark calls. Pairs were retested 10-11 days after pairing (13-17 days after the pre-pairing test). At 7 days 
147 post-pairing, pairs exhibit hallmarks of pair-bonding [48], including increased affiliation and 148 decreased aggression, indicating that 10-11 days is sufficient for pair-bond formation. The playback procedure was the same as in the pre-pairing test except that paired mice were tested

150

151

152

153

154 155

together as a pair (Fig. 2A, right). Both mice were placed into the central chamber and required to enter all three chambers prior to testing. Behavior scoring was the same as in the first test and, additionally, pairs were scored for time spent together in the same chamber. Females generally give birth within 35 days of pairing when housed in cages of similar size to those used in this experiment [37], so were expected to be pregnant at the time of the post-pairing test (gestation 3132 days, [49]). The procedure for unpaired mice was the same as the pre-pairing test. Two unpaired females were removed as they did not enter all three chambers by 10 mins (resulting in 18 females).

\section{IN-OT dose and application}

We administered a $0.8 \mathrm{IU} / \mathrm{kg}$ dose of IN-OT (Bachem, Torrance, CA, Prod \#: 4016373). This dose induces changes in female behavior in rodents [50] and approximates a weight-adjusted dose used in human studies [51]. Intranasal administration is an established, non-invasive route of delivery for OT [52], and intranasally-administered OT enters the brain in house mice (Mus musculus) at behaviorally-relevant concentrations [53]. In California mice, IN-OT produces behavioral effects similar to centrally-administered OT, suggesting that it reaches the brain in this species $[41,54]$. Following pairing, mice were randomly assigned to either saline (mismatched pairs: $\mathrm{N}=15$; matched pairs: $\mathrm{N}=8$ ) or IN-OT treatment (mismatched pairs: $\mathrm{N}=14$; matched pairs: $\mathrm{N}=9$ ) groups. Unpaired females in the follow-up experiment were also randomly assigned to either saline $(\mathrm{N}=10)$ or IN-OT treatment $(\mathrm{N}=8)$ prior to the retest. Immediately prior to the 510 min habituation preceding the retest, females were given either IN-OT or control saline, while all males were administered saline, as this time course has previously been shown to result in 
170 behavioral effects in California mice [40]. To administer, a mouse was scruffed and $25 \mu 1$ of

171 solution was administered to the nostrils using a blunt needle attached to cannula tubing at the end

172 of a Hamilton syringe. Individual droplets were beaded at the end of the syringe, applied to the

173 surface of the nose, and allowed to absorb into the nasal mucosa. Administration lasted less than

17430 s per animal. Only females were given IN-OT because of unpublished data suggesting that IN-

175 OT shifts the convergence/division of labor ratio for pairs defending their territories when given

176 to females, but not males [55].

\section{USV analysis}

We recorded USVs with two ultrasonic microphones (Emkay/Knowles FG, detection range

floor, with one microphone placed in the approach chamber and the other placed in the avoid vocalizations (USVs) [39] important for communication and behavioral coordination [56]. 
193 [16]. Sweeps are of relatively short durations of 30 to $100 \mathrm{~ms}$ with upwards and downwards 194 modulation ranging from 25 to $100 \mathrm{kHz}$ and potentially including multiple inflection points [16]

195 (Fig. 1C). Because audio was recorded for both pair members simultaneously, it was impossible 196 to differentiate calls by each individual so vocalizations were analyzed at the pair level. Both the total number of USV calls produced and the proportion of each USV individual call type produced relative to all call type production were analyzed within this dataset. Four audio files were unusable due to recording setup error (mismatched saline pairs: 11; matched saline pairs: 8; mismatched OT

200

201

202

pairs: 14; matched OT pairs: 9). The length of SVs was also analyzed, and eight pairs that did not produce SVs were removed from this analysis only (mismatched saline pairs: 11; matched saline pairs: 5; mismatched OT pairs: 12; matched OT pairs: 6).

\section{Statistics}

All statistics were analyzed using R (version 3.6.2). We analyzed the female-male approach difference before pairing by taking the absolute value of the difference between female (F) and male $(\mathrm{M})$ approach, $\left|\mathrm{F}_{1}-\mathrm{M}_{1}\right|$ and regressing it on pair type (mismatched or matched) in a general linear model (GLM). We analyzed the degree to which pairs converged by taking the initial difference between pair members, $\left|\mathrm{F}_{1}-\mathrm{M}_{1}\right|$, and subtracting it from the difference at the second test, $\left|\mathrm{F}_{2}-\mathrm{M}_{2}\right|$, and regressed it on pair type, treatment type (saline or IN-OT), and their interaction in a GLM. We analyzed individual changes by subtracting initial approach from approach at the second test $\left(\mathrm{F}_{2}-\mathrm{F}_{1}\right.$ and $\left.\mathrm{M}_{2}-\mathrm{M}_{1}\right)$ and regressed it on pair type, treatment type, and their interaction in a GLM. We likewise analyzed the amount of time pair members spent within the same chamber using pair type, treatment type, and their interaction as factors in a GLM. For changes in vocalizations, we summed vocalizations produced by pairs before pairing and subtracted them from the vocalizations produced in the second test, again using pair type, treatment type, and their interaction as factors 
216 in a GLM. For the proportion of sustained vocalizations (SVs), we looked only at vocalizations

217 produced at the post-pairing test, because there were so few vocalizations produced prior to pairing.

218 We analyzed the proportion of SVs using a GLM with pair type, treatment, and their interaction

219 as factors. We used linear regressions to test if behavior predicted call type proportion. For the

220 separate experiment using unpaired females, we regressed second approach on initial approach,

221 and also analyzed the effects of treatment on approach during the second test, using a GLM. P-

222 values were Holm-Bonferroni corrected for multiple comparisons where appropriate. 


\section{Results}

237 Mismatched pairs had a greater difference in approach scores before pairing than did matched

238 pairs

239 Prior to pairing, a wide range in approach to bark playbacks was found in females (33.43

$240 \pm 4.07$ s s.e.m.) and males (37.96 \pm 4.19 s s.e.m.), with a general linear model (GLM) of approach

241 regressed on sex revealing no mean difference between sexes $(F(1,90)=0.597, p=0.442$; Fig. 2B).

242 Males and females were paired based on their approach, whereby "mismatched" pairs had $\geq 30 \mathrm{~s}$

243 difference in approach score while matched pairs had $\leq 10 \mathrm{~s}$ in their approach score

244 ("mismatched": $\mathrm{N}=16$ pairs female lower than male, $\mathrm{N}=13$ pairs male lower than female;

245 "matched": N=8 pairs female lower than male, N=9 pairs male lower than female; Fig. 2C). As

246 expected, a GLM revealed a statistically significant gap between the approach difference for

247 females and males of mismatched (50.59 \pm 3.11 s s.e.m.) and matched (5.71 \pm 0.83 s s.e.m.) pairs

$248(F(1,44)=118.100, p<0.001 ;$ Fig. 2D $)$ 

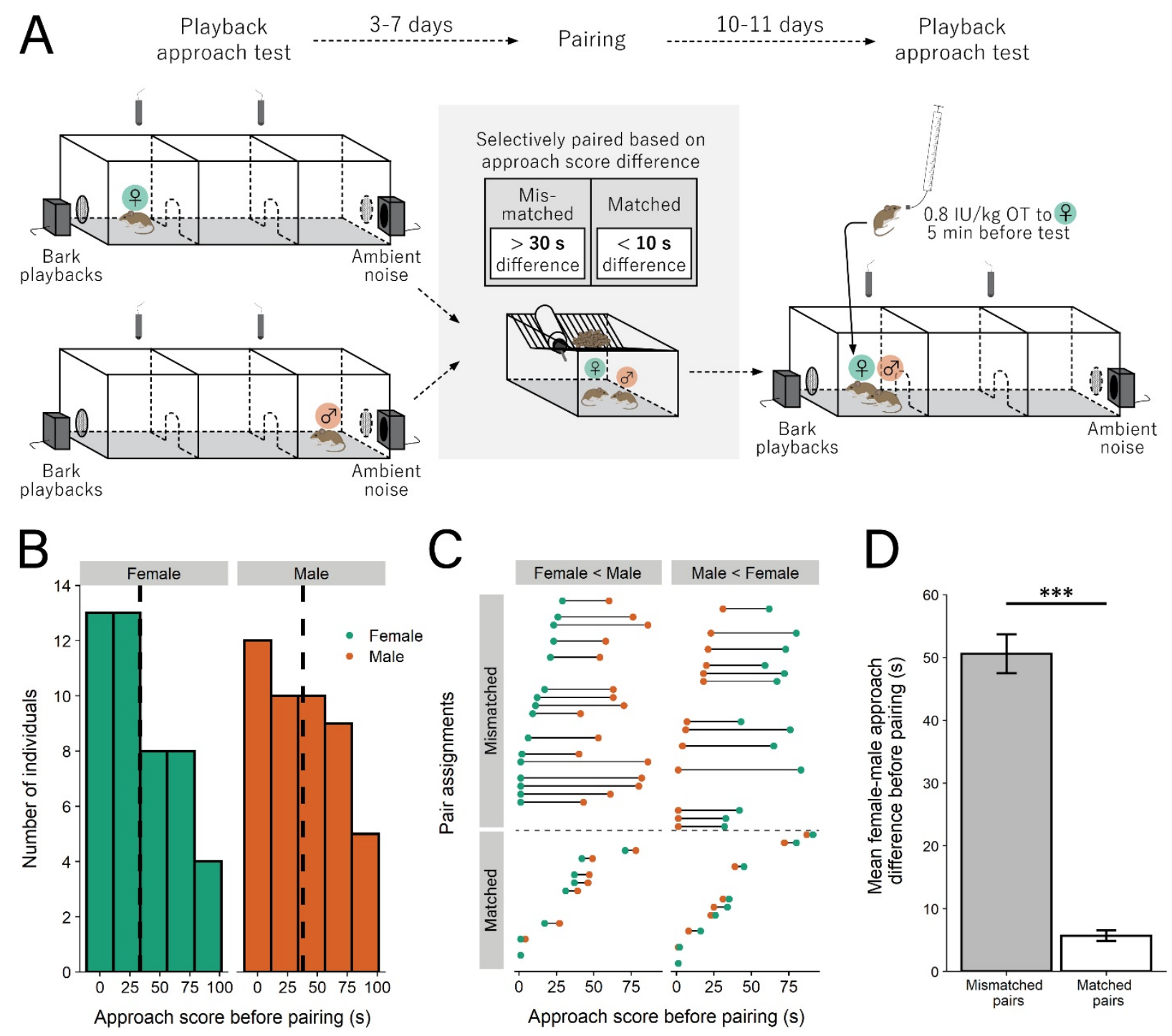

Figure 2. Selective pairing to form mismatched and matched pairs based on initial social approach score. A. Experimental design, adapted from [38, in review]. Approach is the amount of time spent in the chamber closet to the bark playback speaker. B. Distribution of approach scores for females and males before pairing; dotted line is mean approach. C. Stratified randomized pair assignments; mismatched pairs had $\geq 30 \mathrm{~s}$ difference in approach score between mates while matched pairs had $\leq 10$ s difference. D. The female-male approch difference for mismatched pairs was significantly greater than that for matched pairs $(* * *=p<0.001)$. Error bars are \pm s.e.m. 
IN-OT drove mismatched pairs to become more similar than saline mismatched pairs

To determine how IN-OT affected pair convergence, we first assessed the change in approach score difference for matched and mismatched pair mates from the before-pairing test to the after-pairing test. A GLM revealed a significant interaction between pair type (matched or mismatched) and treatment (saline or IN-OT) $(\mathrm{F}(1,42)=4.189, \mathrm{p}=0.047$; Fig. 3A; Table 1A). Controlling for treatment effects, mismatched pairs decreased their approach score difference more than matched pairs from before-pairing to after-pairing, indicating that mismatched pairs become more similar, while matched pairs remain similar $(\mathrm{F}(1,42)=58.346, \mathrm{p}<0.001)$. Relative to saline, IN-OT treatment resulted in a further decrease in approach score difference for mismatched but not matched pairs, as shown by a simple effect of treatment within mismatched pairs, suggesting that IN-OT drove mismatched pairs to become more similar $(F(1,42)=11.539, \mathrm{p}=0.002)$.

From pre-pairing to post-pairing, mismatched and matched IN-OT and saline groups all contained pairs that had pair-averaged approach scores that decreased and pair-averaged approach scores that increased, suggesting that convergence may be driven differently by individuals within pairs (Fig. 3B). To determine whether males and females contribute differently to the overall convergence of pair approach scores, we regressed change in approach from the before-pairing test to the after-pairing test for each individual on the interaction of pair type, treatment, and sex. This GLM revealed no 3-way interaction $(\mathrm{F}(1,84)=0.693, \mathrm{p}=0.408$; Fig. 3C), however, IN-OT individuals in mismatched pairs had a greater change in approach from the before-pairing test to the after-pairing test than did saline individuals in mismatched pairs when controlling for sex, suggesting that the convergence in IN-OT mismatched pairs emerged from changes in approach by both sexes $(\mathrm{F}(1,84)=5.257, \mathrm{p}=0.0244$; Table 1B).

IN-OT increased the amount of time pairs spent in joint approach 

also measured time spent together as an indicator of coordination. Analysis of the amount of time

284 paired mates spent together in either the approach chamber (the chamber closest to the bark 285 playback speaker) or the avoid chamber (the chamber closest to the ambient noise speaker), via a 286 3-way interaction of pair type, treatment, and location, revealed that IN-OT spent significantly 287 more time together in the approach chamber than saline pairs $(F(1,84)=4.311, p=0.041)$ but not 288 in the avoid chamber $(\mathrm{F}(1,84)=0.092, \mathrm{p}=0.762)$, and no main effect of location $(\mathrm{F}(1,84)=0.768$, $289 \mathrm{p}=0.383)$, pair type $(\mathrm{F}(1,84)=1.645, \mathrm{p}=0.203)$, or the full interaction $(\mathrm{F}(1,84)=0.967, \mathrm{p}=$ 290 0.328; Fig. 3D; Table 1C). Additionally, there was a nonsignificant effect of pair type in the avoid 291 chamber for saline groups $(\mathrm{F}(1,84)=3.016, \mathrm{p}=0.086)$. A separate analysis that combined 292 mismatched and matched pairs into a single category also revealed a significant main effect of IN293 OT $(F(1,88)=4.066, p=0.047)$, with a significant simple effect whereby IN-OT increased the 294 amount of time pairs spent together in the approach chamber $(\mathrm{F}(1,88)=4.543, \mathrm{p}=0.036)$ but not 295 the avoid chamber $(\mathrm{F}(1,88)=0.519, \mathrm{p}=0.473$; Fig. 3E). There was also no effect of location $296(\mathrm{~F}(1,88)=0.389, \mathrm{p}=0.535)$ or the interaction of treatment and location $(\mathrm{F}(1,88)=0.996, \mathrm{p}=$ $2970.321)$. 
bioRxiv preprint doi: https://doi.org/10.1101/2020.11.20.390245; this version posted June 17, 2021. The copyright holder for this preprint (which was not certified by peer review) is the author/funder, who has granted bioRxiv a license to display the preprint in perpetuity. It is made available under aCC-BY 4.0 International license.
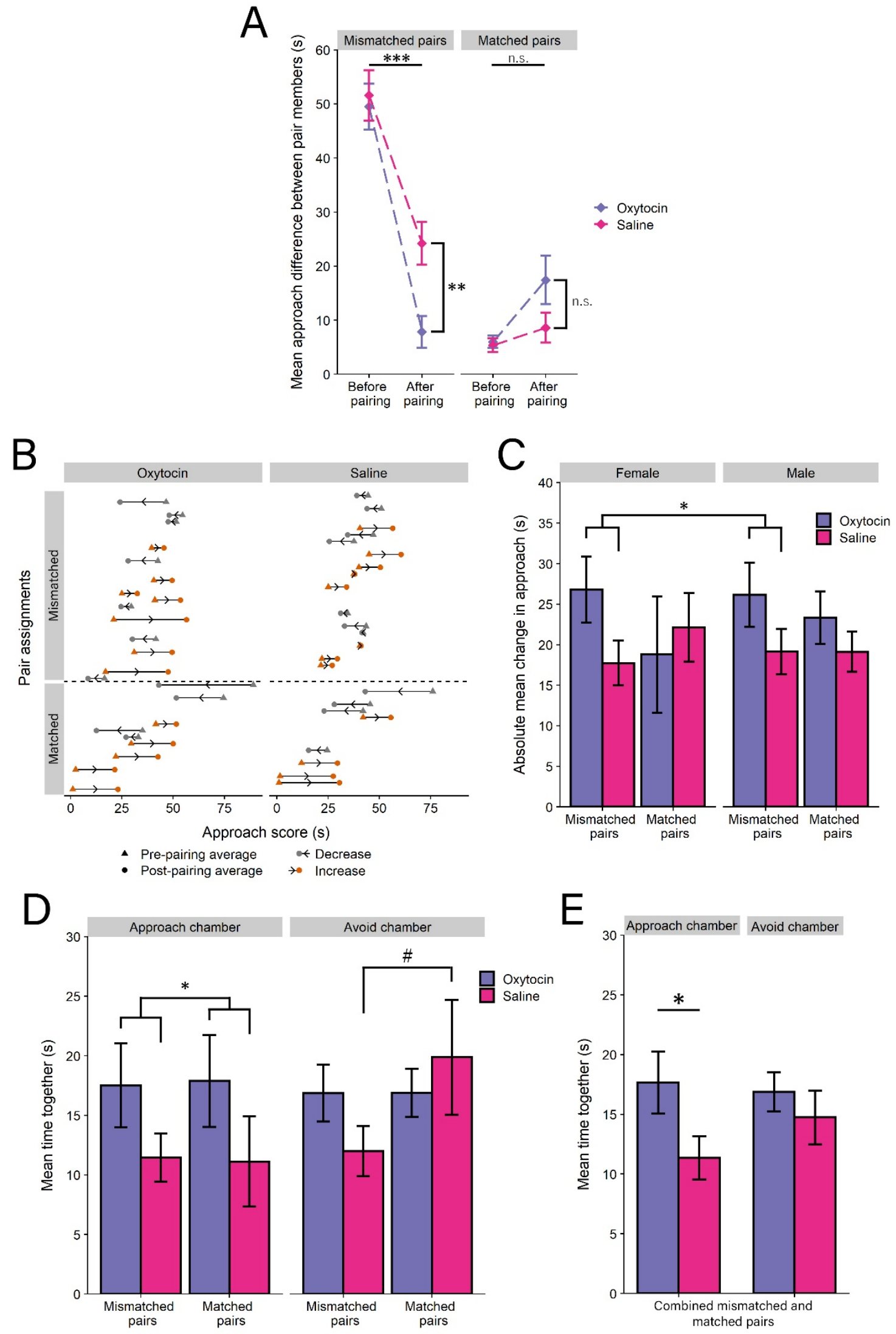
Figure 3. IN-OT drove mismatched pair mates to converge more in their social approach and pairs to increase their joint approach. A. Mismatched pair mates became more matched, an effect enhanced by OT, while matched pairs remained matched and were unaffected by OT. B. Withinpair average approach increased and decreased by pair for mismatched and matched OT and saline groups. C. Females and males of OT mismatched pairs changed their approach more than females and males of saline mismatched pairs. D. IN-OT increased the amount of time OT pair mates spent together in the approach chamber. D. Time together in the approach chamber and avoid chamber, aggregated for all pairs. (n.s. = not significant; $\#=p<0.10 ; *=p<0.05 ; * *=p<0.01 ; * * *=p$ $<0.001)$. Error bars are \pm s.e.m.

\section{Mismatched pairs produced a higher proportion of sustained vocalizations after pairing, which} was not affected by IN-OT

To determine how pair type and IN-OT affected vocal production, we assessed the number and type of USVs produced in the pre-pairing and post-pairing tests. A GLM revealed a significant increase in the total number of vocalizations produced by pairs relative to the sum of vocalizations for pair members before pairing $(\mathrm{F}(1,38)=70.267, \mathrm{p}<0.001)$, but no significant interaction between pair type and treatment $(F(1,38)=2.182, \mathrm{p}=0.148$; Fig. 4A). Similarly, a GLM for number of sweeps $(\mathrm{F}(1,38)=66.182, \mathrm{p}<0.001)$ indicated significant increases in sweep production after pairing, but no significant interaction $(F(1,38)=2.184, p=0.148$; Fig. 4B). A GLM for number of sustained vocalizations (SVs) revealed a significant increase in SV production after pairing $(\mathrm{F}(1,38)=35.168, \mathrm{p}<0.001)$ as well as a nonsignificant increase in SV production by mismatched pairs $(\mathrm{F}(1,38)=3.801, \mathrm{p}=0.059)$, but no main effect of treatment $(\mathrm{F}(1,38)=0.799$, $\mathrm{p}=0.377)$ or significant interaction $(\mathrm{F}(1,38)=0.106, \mathrm{p}=0.747$; Fig. 4C; Table 1D). Taken together, this suggests that pairing increases the total number of sweeps and SVs that are produced, and that pair type and IN-OT do not affect the total number of either sweeps or SVs. 
We next assessed whether other features of SV call production were affected by pair type

325

326

327

328

329

330

or IN-OT. A GLM revealed that mismatched pairs significantly increased the proportion of SVs produced after pairing (as used in [57]) $(\mathrm{F}(1,38)=4.141, \mathrm{p}=0.048)$, but that there was no significant interaction with IN-OT $(\mathrm{F}(1,38)=0.298, \mathrm{p}=0.588$; Fig. 4D, Table 1E). A GLM indicated no significant effect of pair type $(\mathrm{F}(1,31)=0.475, \mathrm{p}=0.496)$, treatment $(\mathrm{F}(1,31)=0.069$, $\mathrm{p}=0.795)$, or interaction $(\mathrm{F}(1,31)=0.489, \mathrm{p}=0.490)$ on SV length (Fig. 4E, Table 1E). These results indicate that SV proportion may be involved in pair convergence.

Sustained vocalization proportion positively correlated with pair similarity and negatively correlated with time IN-OT-treated pairs spent together in the approach chamber

To determine whether SV proportion after pairing was associated with pair coordination, we correlated SV proportion of pairs with convergence and treatment, and then joint approach and treatment. A GLM revealed a significant main effect of the degree of convergence (|F2-M2| - |F1$\mathrm{M} 1 \mid)$ on the proportion of SVs produced after pairing $(\mathrm{F}(1,38)=4.476, \mathrm{p}=0.041$; Fig. $4 \mathrm{~F})$, showing that the degree to which pairs become more similar is positively correlated with SV production. However, there was no significant interaction between pair type and treatment $(\mathrm{F}(1,38)$ $=0.595, \mathrm{p}=0.445)$ or main effect of treatment $(\mathrm{F}(1,38)=0.105, \mathrm{p}=0.748)$, suggesting that INOT did not have an effect on the relationship between SV proportion and convergence.

A separate GLM revealed a significant interaction between the amount of time pairs spent together in the approach chamber and treatment type on the proportion of SVs produced $(\mathrm{F}(1,38)$ $=5.000, \mathrm{p}=0.031$, Fig. $4 \mathrm{G})$, with a significant simple effect of IN-OT $(\mathrm{F}(1,38)=10.440, \mathrm{p}=$ 0.003 ) but not saline $(\mathrm{F}(1,38)=0.280, \mathrm{p}=0.600)$, indicating that increased time spent together in the approach chamber for IN-OT pairs was associated with decreasing SV proportion. 
bioRxiv preprint doi: https://doi.org/10.1101/2020.11.20.390245; this version posted June 17, 2021. The copyright holder for this preprint (which was not certified by peer review) is the author/funder, who has granted bioRxiv a license to display the preprint in perpetuity. It is made available under aCC-BY 4.0 International license.
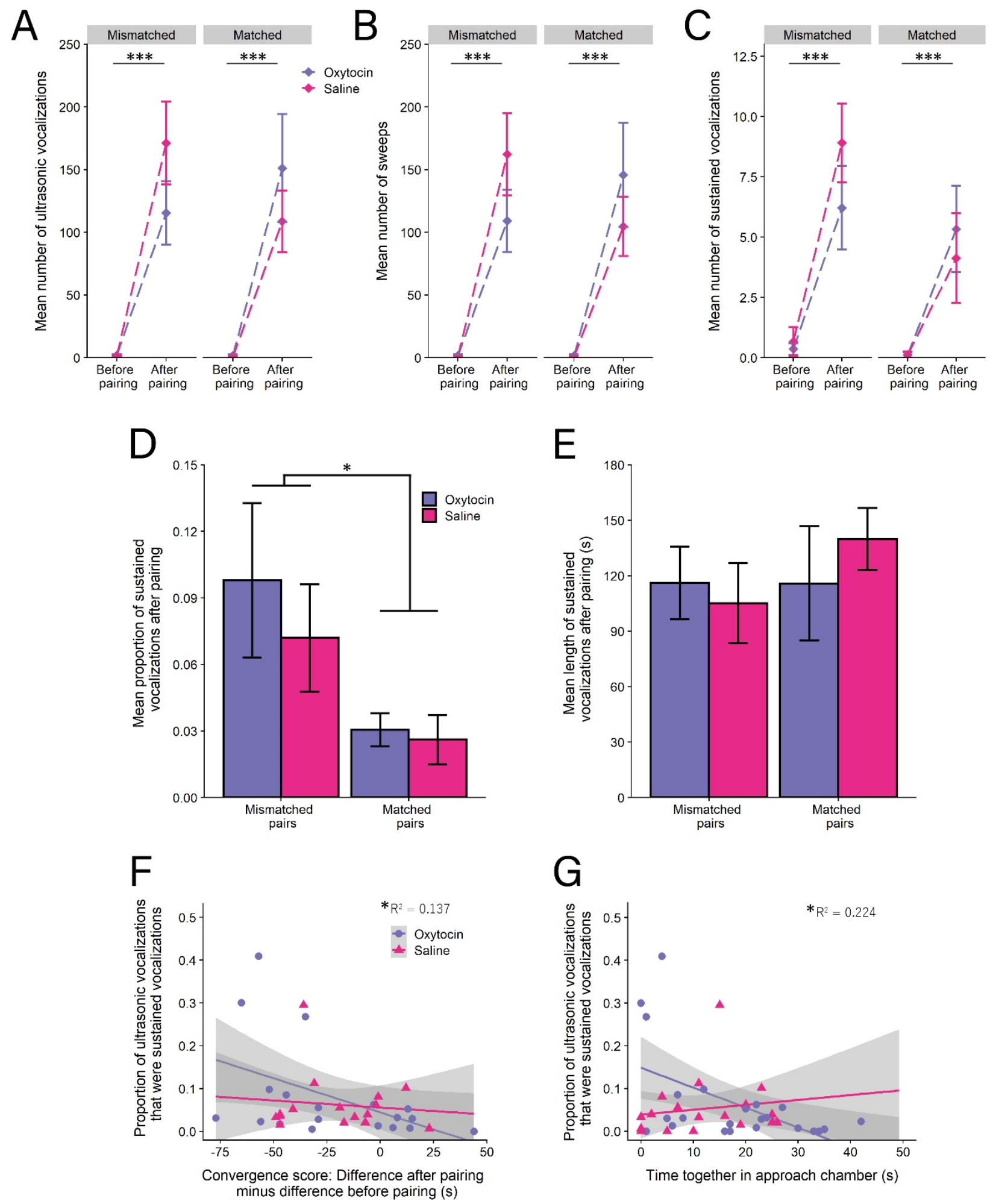
346 Figure 4. Pair type and IN-OT altered the production of ultrasonic vocalizations. A, B, C. Pairing 347 resulted in a profound increase in the number of ultrasonic vocalizations produced, including 348 sweeps and sustained vocalizations, across pair type and treatment. D. Mismatched pairs produced 349 a greater proportion of sustained vocalizations. E. Length of sustained vocalizations did not differ 350 by pair type or treatment condition. F.The degree to which pair mates converged predicted the 351 proportion of sustained vocalzations produced after pairing. A negative number on the x-axis 352 shows pair mates decreased the difference in approach score from the first test to the second test,

353 indicating convergence. G. IN-OT and time spent together in the approach chamber negatively 354 predicted the proportion of SVs produced. $(*=\mathrm{p}<0.05 ; * * * \mathrm{p}<0.001)$. Error bars are \pm s.e.m.

In order to demonstrate that approach behavior is repeatable and to investigate the effects of the IN-OT treatment in unpaired individuals, a separate cohort of unpaired females was tested for initial response and response 13-17 days later, the same length of time as that between the prepairing and post-pairing test for paired mice. A GLM revealed that initial approach reliably

362 predicts later approach $(\mathrm{F}(1,14)=14.59, \mathrm{p}=0.002$; Fig. $5 \mathrm{~A})$, with no significant main effect of 363 treatment $(\mathrm{F}(1,14)=0.313, \mathrm{p}=0.585)$ or interaction $(\mathrm{F}(1,14)=0.227, \mathrm{p}=0.641)$. A separate GLM 364 indicated no effect of treatment on approach during the second test $(F(1,16)=0.415, p=0.529$; 365 Fig. 5B). 

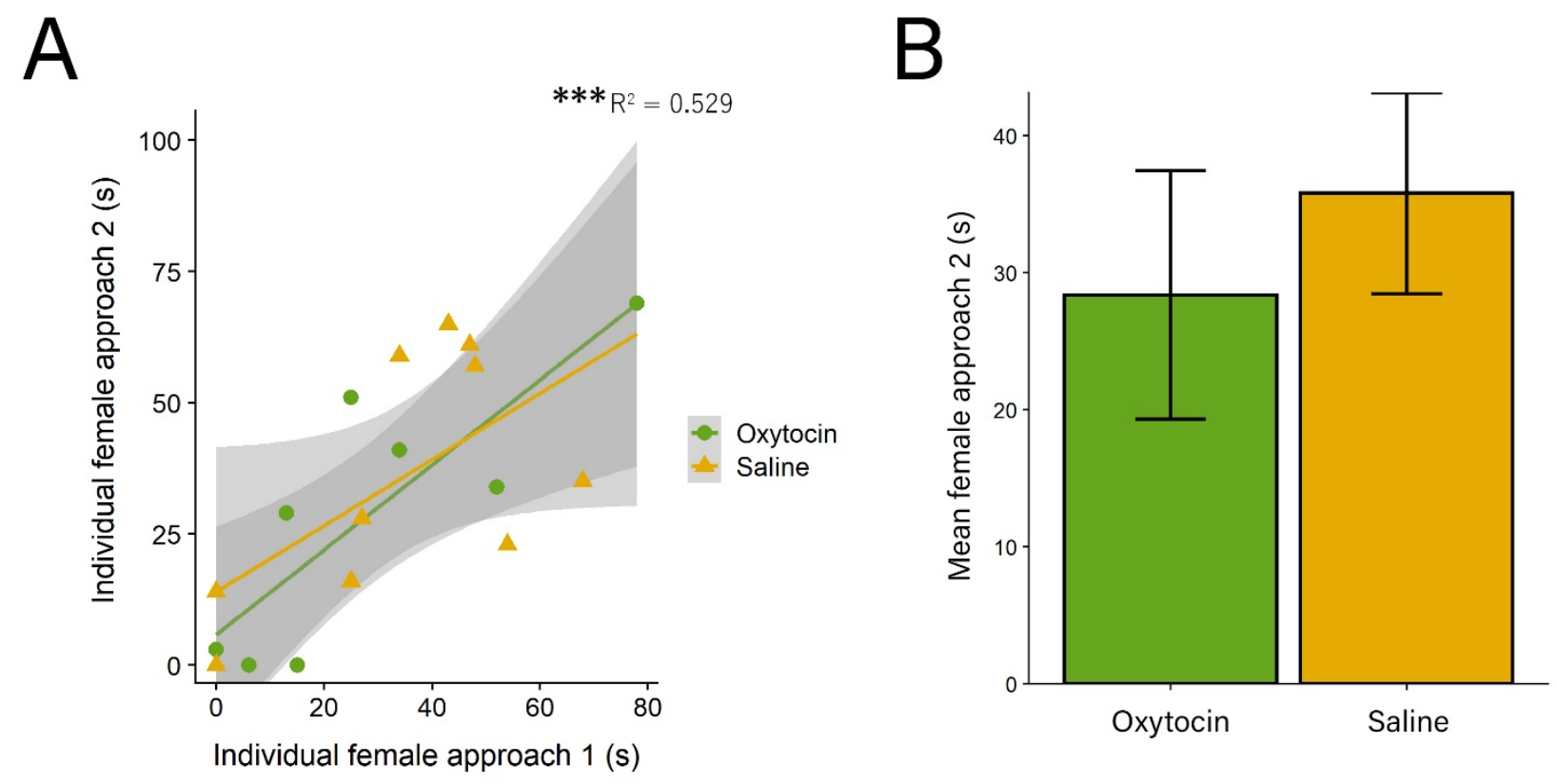

Figure 5. A separate cohort of unpaired females showed high test-retest reliability. A. Unpaired females showed reliable response to the playback approach test 13-17 later. B. IN-OT did not significantly change female approach at the second test. $(* * *=p<0.001)$. Error bars are \pm s.e.m. 
bioRxiv preprint doi: https://doi.org/10.1101/2020.11.20.390245: this version posted June 17, 2021. The copyright holder for this preprint (which was not certified by peer review) is the author/funder, who has granted bioRxiv a license to display the preprint in perpetuity. It is made available under aCC-BY 4.0 International license.

\begin{tabular}{|l|l|l|l|l|l|l|}
\cline { 2 - 7 } & \multicolumn{2}{|l|}{$\begin{array}{l}\text { Female-male approach difference } \\
\text { before pairing }(|\mathrm{F} 1-\mathrm{M} 1|)(\mathrm{s}) \pm \\
\text { s.e.m. }\end{array}$} & $\begin{array}{l}\text { Female-male approach } \\
\text { difference after pairing } \\
(|\mathrm{F} 2-\mathrm{M} 2|)(\mathrm{s}) \pm \text { s.e.m. }\end{array}$ & $\begin{array}{l}\Delta \text { approach difference from before } \\
\text { pairing to after pairing } \\
(|\mathrm{F} 2-\mathrm{M} 2|-|\mathrm{F} 1-\mathrm{M} 1|)(\mathrm{s}) \pm \text { s.e.m. }\end{array}$ \\
\cline { 2 - 7 } & Saline & Oxytocin & Saline & Oxytocin & Saline & Oxytocin \\
\hline Mismatched & $51.60 \pm 4.66$ & $49.50 \pm 4.24$ & $24.20 \pm 3.98$ & $7.86 \pm 2.92$ & $-27.40 \pm 4.88$ & $-41.64 \pm 5.83$ \\
\hline Matched & $5.38 \pm 1.28$ & $6.00 \pm 1.13$ & $8.63 \pm 2.78$ & $17.44 \pm 4.47$ & $3.25 \pm 3.62$ & $11.44 \pm 4.66$ \\
\hline
\end{tabular}

\begin{tabular}{|l|l|l|l|l|}
\cline { 2 - 5 } $\mathbf{B}$ & \multicolumn{2}{|l|}{$\begin{array}{l}\text { Female } \Delta \text { approach from before } \\
\text { pairing to after pairing }(|\mathrm{F} 2-\mathrm{F} 1|)(\mathrm{s}) \\
\pm \text { s.e.m. }\end{array}$} & $\begin{array}{l}\text { Male } \Delta \text { approach from } \\
\text { before pairing to after } \\
\text { pairing }(|\mathrm{M} 2-\mathrm{M} 1|)(\mathrm{s}) \pm \\
\text { s.e.m. }\end{array}$ \\
\cline { 2 - 5 } \multicolumn{1}{|l|}{ Saline } & Oxytocin & Saline & Oxytocin \\
\hline Mismatched & $17.73 \pm 2.76$ & $26.79 \pm 4.06$ & $19.13 \pm 2.80$ & $26.14 \pm 3.97$ \\
\hline Matched & $22.13 \pm 4.21$ & $18.78 \pm 7.20$ & $19.13 \pm 2.47$ & $23.33 \pm 3.25$ \\
\hline
\end{tabular}

\begin{tabular}{|l|l|l|l|l|}
\cline { 2 - 5 } \multicolumn{1}{c|}{} & \multicolumn{2}{l|}{$\begin{array}{l}\text { Time together in approach } \\
\text { chamber (s) } \pm \text { s.e.m. }\end{array}$} & \multicolumn{2}{l|}{$\begin{array}{l}\text { Time together in avoid } \\
\text { chambers (s) } \pm \text { s.e.m. }\end{array}$} \\
\cline { 2 - 5 } \multicolumn{1}{c|}{} & Saline & Oxytocin & Saline & Oxytocin \\
\hline Mismatched & $11.47 \pm 2.01$ & $17.50 \pm 3.53$ & $12.00 \pm 2.10$ & $16.86 \pm 2.38$ \\
\hline Matched & $11.13 \pm 3.78$ & $17.89 \pm 3.86$ & $19.88 \pm 4.81$ & $16.89 \pm 2.01$ \\
\hline Aggregate & $11.35 \pm 1.81$ & $17.65 \pm 2.57$ & $14.74 \pm 2.24$ & $16.87 \pm 1.62$ \\
\hline
\end{tabular}

\begin{tabular}{|l|l|l|l|l|l|l|l|l|}
\cline { 2 - 9 } \multicolumn{1}{l|}{} & \multicolumn{2}{|l|}{$\begin{array}{l}\Delta \text { total ultrasonic vocalizations } \pm \\
\text { s.e.m. }\end{array}$} & $\begin{array}{l}\Delta \text { sustained vocalizations } \pm \\
\text { s.e.m. }\end{array}$ & \multicolumn{2}{l|}{$\Delta$ sweeps \pm s.e.m. } & \multicolumn{2}{l|}{$\Delta$ barks \pm s.e.m. } \\
\cline { 2 - 9 } \multicolumn{1}{l|}{ Saline } & Oxytocin & Saline & Oxytocin & Saline & Oxytocin & Saline & Oxytocin \\
\hline Mismatched & $171.09 \pm 33.05$ & $115.36 \pm 25.34$ & $8.00 \pm 1.76$ & $5.86 \pm 1.65$ & $161.09 \pm 32.62$ & $107.57 \pm 24.86$ & $0.00 \pm 0.00$ & $0.00 \pm 0.00$ \\
\hline Matched & $108.75 \pm 24.67$ & $148.89 \pm 42.60$ & $4.00 \pm 1.91$ & $3.00 \pm 1.39$ & $103.88 \pm 23.80$ & $144.22 \pm 41.42$ & $0.00 \pm 0.00$ & $0.00 \pm 0.00$ \\
\hline
\end{tabular}

\begin{tabular}{|l|l|l|l|l|}
\cline { 2 - 5 } \multicolumn{1}{c|}{$\mathbf{E}$} & \multicolumn{2}{|l|}{$\begin{array}{l}\text { Sustained vocalization proportion } \\
\text { after pairing } \pm \text { s.e.m. }\end{array}$} & \multicolumn{2}{l}{$\begin{array}{l}\text { Sustained vocalization length after } \\
\text { pairing }(\mathrm{ms}) \pm \text { s.e.m. }\end{array}$} \\
\cline { 2 - 5 } & Saline & Oxytocin & Saline & Oxytocin \\
\hline Mismatched & $0.072 \pm 0.024$ & $0.098 \pm 0.035$ & $105.20 \pm 21.72$ & $116.08 \pm 19.72$ \\
\hline Matched & $0.026 \pm 0.011$ & $0.031 \pm 0.007$ & $139.82 \pm 16.80$ & $115.84 \pm 30.94$ \\
\hline
\end{tabular}

383 Table 1. Descriptive table of mean group values. A. Approach differences between paired mates. 384 B. Approach differences for individuals. C. Time spent together by pairs. D. Changes in aggregate 385 vocalizations from before pairing to after pairing. E. Proportion of ultrasonic vocalizations that 386 were sustained vocalizations after pairing. 


\section{Discussion}

The social salience hypothesis argues that oxytocin (OT) attunes individuals to social context [24], possibly explaining why OT is able to induce both social avoidance [19] and social approach [41]. However, the roles of affiliative bonds in this process have remained elusive. Here we used a pre-post pairing design and found that OT facilitates pair-bonding-induced changes in social behavior and coordination. Intranasal OT (IN-OT), when given to female California mice, produced pair-level shifts in social approach of an aggressive bark stimulus driving mismatched pair mates to become more similar. Analysis of time spent in proximity showed that IN-OT drove pairs to spend more time together approaching the stimulus, likely producing the shift towards pair similarity and indicating coordinating effects of OT beyond bonding in these already bonded pair members. Recordings of USVs revealed that IN-OT drove the negative correlation between the ratio of SVs and time spent together in approach. Finally, unpaired females demonstrated a high degree of repeatability in their approach, which was not affected by IN-OT. These data suggest that the social context of pair bonding alters social approach, that the degree to which an individual alters their social approach depends on their partner, and that OT facilitates pair-bondingdependent changes in social approach. Our results are consistent with a social convergence theory, whereby OT unites pair-bonded individuals in the face of challenge, and that this coordination may be related to changes in the proportions of vocalization types produced.

Recently, two other Peromyscus species were shown to have repeatability in behavior and correlation between boldness behaviors [59], and other consistent individual differences have been found in Peromyscus species [60], including California mice [39]. We extend these findings to consider the change in behavior type resulting from the presence of a pair member, and vocalizations and OT signaling as behavioral and hormonal mechanisms, respectively, under 
415 affiliative social contexts. We observed that IN-OT given to females increased convergence in 416 approach scores for initially mismatched pairs but had no effect on either the convergence of pairs

417 that were initially matched or on total time unpaired females spent approaching the simulated

418 intruder, suggesting that OT changes in behavior may be related to a motivation to maintain partner

419 proximity in response to a single stimulus. While convergence has been shown to be asymmetrical

420 in convict cichlids, with the more reactive partners being more flexible than proactive partners

421 [43], we show that in California mice both individuals with low and high initial levels of social

422 approach change their behavior in response to pairing. Our results can be interpreted as

423 adjustments by both pair members to become more similar in behavioral type to their partners, and

424 not solely within-individual variation in approach response from the pre-pairing to the post-pairing

425 test, because unpaired individuals showed repeatable responses to the vocalization playback

426 stimuli. Taken together, our study provides experimental evidence of pair type-dependent changes

427 to social behavior that are facilitated by female OT signaling, and is consistent with prior evidence

428 of convergence by mismatched pairs [38, in review]. Moreover, it suggests that although individual

429 unpaired females demonstrate reliable and consistent approach behavior even in response to IN-

430 OT, the change in approach behavior induced by pairing mismatched individuals is malleable in

431 response to IN-OT.

Several hypotheses emerge for why IN-OT drives changes in behavior. First, it is possible

433 that social approach reflects underlying differences in stress and stress susceptibility, as the

434 stressed state of an individual influences both social approach and OT signaling. Social defeat 435 stress decreases OT receptor (OTR) gene expression in female California mice [19] and reduced

436 OTR binding in the NAc corresponds to reduced social approach following defeat [61]. Moreover,

437 plasma OT levels have been positively linked to attachment anxiety in romantic human 
438 relationships [62], and pair bonding influences affective state across taxa [63,64]. Because we did

439 not directly measure stress or anxiety, we are unable to correlate individual differences in stress

440 response to social approach or pair bonding-induced convergence. However, while IN-OT may

441 have influenced anxiety-like behavior, the lack of IN-OT to change social approach in unpaired

442 individuals suggests no baseline interaction between stress and OT.

Another hypothesis for why IN-OT drove changes in behavior is that it increased the

444 motivation to bond. While it is possible that the behavioral convergence reflects a motivation to

445 stay closer together to maintain the pair bond, the second test occurred after the pairs were stably

446 bonded. IN-OT likely induced coordination of behavior beyond bonding, as evidenced by the

447 increase in time IN-OT pairs spent jointly approaching the stimulus, but not jointly avoiding.

448 Further evidence is suggested by the vocalization data: In this study we tracked two call types,

449 sustained vocalizations (SVs) and sweeps, because they may play a role in pair bond formation

450 and maintenance [58]. While mismatched pairs produced a higher proportion of sustained

451 vocalizations, indicating a potential behavioral mechanism underlying this coordination, IN-OT

452 drove a negative correlation between SV proportion and time spent together in the approach

453 chamber, suggesting that OT may be involved in the relationship between decreased SV

454 production and behavioral convergence. We found no difference in SV length between groups,

455 which has previously been shown to be a relevant characteristic for bonding pairs, with longer SVs

456 produced over the first week of pairing [56]. However, different results might have occurred if we

457 had recorded individual USVs as opposed to pair USVs. Moreover, the SVs in this study were

458 relatively short compared to those found by other studies (an average of about $115 \mathrm{~ms}$ compared

459 to, for example, an average of about $175 \mathrm{~ms}$ in [48]), but similar to those observed during 
to do so when given to mothers interacting with their pups [40]. This effect was context-dependent

472 such that OT increased sweeps in mothers only when mothers were in physical contact with their

473 pups. In the current study we observed an increase in sweeps in response to pairing as expected by

474 [48], but IN-OT did not increase production of sweeps. The reason for this is unknown, however,

475 it is possibly because the playbacks resulted in a less affiliative interaction, or that IN-OT effects

476

aggressive encounters (for example, an average of about $105 \mathrm{~ms}$ in [16]) which may indicate negotiation or negative affect by pairs in this novel context.

Finally, another hypothesis for why IN-OT drove changes in behavior relates to pair coordination and synchrony. Synchrony, an emergent behavior that occurs between two or more individuals, such as eye contact, singing, or movement, is linked to greater affiliation and cooperation [65]. California mice are socially monogamous and form strong affiliative bonds that last for life [66]; OT may increase the ability of pair-bonded individuals in monogamous, biparental species to perceive a partner's intent and thus provide complimentary behaviors to efficiently address environmental challenges such as foraging, defending against predators, and taking care of young.

It is interesting to note that IN-OT did not increase sweeps as it has previously been shown are restricted to mother-pup interactions.

Overall our results suggest that OT modulates social approach in a social contextdependent fashion by driving initially mismatched pairs to become more matched by increasing time spent in joint navigation, consistent with previous findings that OT signaling is critical to both bonding [67] and social coordination [23]. Taken together these results suggest that affiliative social context is critical for OT-regulated social approach and vigilance. An important direction for future studies is determine the neural circuitry overlap between social approach and affiliative 
bioRxiv preprint doi: https://doi.org/10.1101/2020.1120.390245; this version posted June 17, 2021. The copyright holder for this preprint (which was not certified by peer review) is the author/funder, who has granted bioRxiv a license to display the preprint in perpetuity. It is made available under aCC-BY 4.0 International license.

483 bonding. Our results are in line with calls for researchers to consider social context when studying

484 behavioral types $[68,69]$.

485

486

487

488

489

490

491

492

493

494

495

496

497

498

499

500

501

502 


\section{Acknowledgements}

Research was conducted at the University of Wisconsin-Madison, which occupies the ancestral Ho-Chunk land known as Teejop. Following an 1832 treaty, federal and state governments

506

507

508

509

510

511

512

\section{Competing interests}

514 Authors declare no competing interests. repeatedly, but unsuccessfully, sought to forcibly remove the Ho-Chunk from Wisconsin [70]. As members of a land grant institution we directly benefit from land theft, and we challenge ourselves and others to reflect on the perpetuation of the colonialist roots of western scientific progress. A. Auger, L. Riters, C. Guoynes, and C. Malone provided manuscript feedback, and Z. Herro and T. Nguyen helped with data collection. We also thank the UW-Madison animal research technicians. Research was supported by the National Science Foundation (IOS-1946613 and DGE-1747503).

\section{Contributions}

517 PKM, NSR, and CAM designed the study, PKM and JS conducted the experiments and data 518 collection, PKM analyzed data, PKM wrote the initial draft of the manuscript, CAM and NSR 519 provided guidance during analyses, and all authors contributed to the writing and review of the 520 manuscript.

\section{Data accessibility}

523 Data available from the Open Science Framework: https://osf.io/2a8gm/ 


\section{References}

525

526

527

528

529

530

531

532

533

534

535

536

537

538

539

540

541

542

543

544

545

546

547

548

549

550

551

552

553

554

555

556

557

558

559

560

561

1. Dillard JR, Westneat DF. Disentangling the Correlated Evolution of Monogamy and Cooperation. Trends Ecol Evol. 2016;31(7):503-13.

2. French JA, Cavanaugh J, Mustoe A, Carp S. Social Monogamy in Nonhuman Primates: Phylogeny, Phenotype, and Physiology. J Sex Res. 2018;55(4-5):410-34.

3. Klug H. Why monogamy? A review of potential ultimate drivers. Front Ecol Evol. 2018;6:30.

4. Mayer M, Zedrosser A, Rosell F. Extra-territorial movements differ between territory holders and subordinates in a large, monogamous rodent. Sci Rep. 2017;7(1):1-10.

5. Dally JM, Emery NJ, Clayton NS. The Social Suppression of Caching in Western ScrubJays (Aphelocoma californica). Behaviour. 2005;142(7):961-77.

6. Borries C, Savini T, Koenig A. Social monogamy and the threat of infanticide in larger mammals. Behav Ecol Sociobiol. 2011;65(4):685-93.

7. Both C; Visser ME. Breeding territory size affects fitness: an experimental study on competition at the individual level. J Anim Ecol. 2000;69(6):1021-30.

8. Thomas DW, Blondel J, Perret P, Lambrechts MM, Speakman JR. Energetic and Fitness Costs of Mismatching Resource Supply and Demand in Seasonally Breeding Birds. Science (80- ). 2001;291(5513):2598-600.

9. Agrell J, Wolff JO, Ylönen H. Counter-Strategies to Infanticide in Mammals: Costs and Consequences. Oikos. 1998;83(3):507-17.

10. Rogers W. Parental Investment and Division of Labor in the Midas Cichlid (Cichlasoma citrinellum). Ethology. 1988;79(2):126-42.

11. Brotherton, Peter NM, Pemberton JM, Komers PE, Malarky G. Genetic and behavioural evidence of monogamy in a mammal, Kirk's dik-dik (Madoqua kirkii). Proc R Soc B Biol Sci. 1997;264(1382):675-81.

12. Thomas JA, Birney EC. Parental care and mating system of the prairie vole, Microtus ochrogaster. Behav Ecol Sociobiol. 1979;5(2):171-86.

13. Ahern TH, Hammock EAD, Young LJ. Parental division of labor, coordination, and the effects of family structure on parenting in monogamous prairie voles (Microtus ochrogaster). Dev Psychobiol. 2011;53(2):118-31.

14. Frazier CRMM, Trainor BC, Cravens CJ, Whitney TK, Marler CA. Paternal behavior influences development of aggression and vasopressin expression in male California mouse offspring. Horm Behav. 2006;50(5):699-707.

15. Marler CA, Trainor BC, Gleason ED, Bester-Meredith JK, Becker EA. The Effects of Paternal Behavior on Offspring Aggression and Hormones in the Biparental California Mouse. Neurobiol Parent Brain. 2008;435-48.

16. Rieger NS, Marler CA. The function of ultrasonic vocalizations during territorial defence by pair-bonded male and female California mice. Anim Behav. 2018;135:97-108. 
17. Olff M, Frijling JL, Kubzansky LD, Bradley B, Ellenbogen MA, Cardoso C, Bartz JA, Yee JR, van Zuiden M. The role of oxytocin in social bonding, stress regulation and mental health: An update on the moderating effects of context and interindividual differences. Psychoneuroendocrinology. 2013;38(9):1883-94.

18. Ditzen B, Schaer M, Gabriel B, Bodenmann G, Ehlert U, Heinrichs M. Intranasal Oxytocin Increases Positive Communication and Reduces Cortisol Levels During Couple Conflict. Biol Psychiatry. 2009;65(9):728-31.

19. Williams A V., Duque-Wilckens N, Ramos-Maciel S, Campi KL, Bhela SK, Xu CK, Jackson K, Chini B, Pesavento PA, Trainor BC. Social approach and social vigilance are differentially regulated by oxytocin receptors in the nucleus accumbens. Neuropsychopharmacology. 2020;45(9):1423-30.

20. Eckstein M, Scheele D, Weber K, Stoffel-Wagner B, Maier W, Hurlemann R. Oxytocin facilitates the sensation of social stress. Hum Brain Mapp. 2014;35(9):4741-50.

21. Shamay-Tsoory SG, Fischer M, Dvash J, Harari H, Perach-Bloom N, Levkovitz Y. Intranasal Administration of Oxytocin Increases Envy and Schadenfreude (Gloating). Biol Psychiatry. 2009;66(9):864-70.

22. DeWall CN, Gillath O, Pressman SD, Black LL, Bartz JA, Moskovitz J, Stetler DA. When the Love Hormone Leads to Violence: Oxytocin Increases Intimate Partner Violence Inclinations Among High Trait Aggressive People. Soc Psychol Personal Sci. 2014;5(6):691-7.

23. De Dreu CK, Greer LL, Kleef GA Van, Shalvi S, Handgraaf MJ. Oxytocin promotes human ethnocentrism. Proc Natl Acad Sci. 2011;108(4):1262-6.

24. Shamay-Tsoory SG, Abu-Akel A. The Social Salience Hypothesis of Oxytocin. Biol Psychiatry. 2016;79(3):194-202.

25. Harari-Dahan O, Bernstein A. A general approach - avoidance hypothesis of Oxytocin: Accounting for social and non-social effects of oxytocin. Neurosci Biobehav Rev. 2014;47:506-19.

26. Kemp AH, Guastella AJ. The role of oxytocin in human affect: A novel hypothesis. Curr Dir Psychol Sci. 2011;20(4):222-31.

27. Cavanaugh J, Mustoe A, Womack SL, French JA. Oxytocin modulates mate-guarding behavior in marmoset monkeys. Horm Behav. 2018;106:150-61.

28. Marsh N, Scheele D, Feinstein JS, Gerhardt H, Strang S, Maier W, Hurlemann R. Oxytocin-enforced norm compliance reduces xenophobic outgroup rejection. Proc Natl Acad Sci. 2017;114(35):9314-9.

29. Wey TW, Vrana PB, Mabry KE. Mating system as a possible driver of behavioral diversity in Peromyscus. Behav Ecol Sociobiol. 2017;71(11):163.

30. Merritt JF. Peromyscus californicus. Mamm Species. 1978;(85):1.

31. Gubernick DJ, Cully Nordby J. Behavioral Ecology and Sociobiology Mechanisms of sexual fidelity in the monogamous California mouse, Peromyscus californicus. Behav Ecol Sociobiol. 1993;32:211-9. 
32. Trainor BC, Marler CA. Testosterone, Paternal Behavior, and Aggression in the Monogamous California Mouse (Peromyscus californicus). Horm Behav. 2001;40(1):3242.

33. Bester-Meredith JK, Young LJ, Marler CA. Species differences in paternal behavior and aggression in Peromyscus and their associations with vasopressin immunoreactivity and receptors. Horm Behav. 1999;36(1):25-38.

34. Davis ES, Marler CA. The progesterone challenge: Steroid hormone changes following a simulated territorial intrusion in female Peromyscus californicus. Horm Behav. 2003;44(3):185-98.

35. Marler CA, Oyegbile TO, Marler CA. Winning fights elevates testosterone levels in California mice and enhances future ability to win fights. Horm Behav. 2005;48(3):25967.

36. Fuxjager MJ, Mast G, Becker EA, Marler CA. The "home advantage" is necessary for a full winner effect and changes in post-encounter testosterone. Horm Behav. 2009;56(2):214-9.

37. Rieger NS, Stanton EH, Marler CA. Division of labour in territorial defence and pup retrieval by pair-bonded California mice, Peromyscus californicus. Anim Behav. 2019; 156:67-78.

38. Rieger NS, Monari PK, Hartfield K, Schefelker J, Marler CA. Pair-bonding leads to convergence in approach behavior to conspecific vocalizations in California mice (Peromyscus californicus). Manuscript submitted for publication. 2021.

39. Kalcounis-Rueppell MC, Pultorak JD, Marler CA. Ultrasonic Vocalizations of Mice in the Genus Peromyscus. Handb Behav Neurosci. 2018;25:227-35.

40. Guoynes CD, Marler CA. An acute dose of intranasal oxytocin rapidly increases maternal communication and maintains maternal care in primiparous postpartum California mice. PLoS One. 2021;16(4 April 2021):e0244033.

41. Steinman MQ, Duque-Wilckens N, Greenberg GD, Hao R, Campi KL, Laredo SA, Laman-Maharg A, Manning CE, Doig IE, Lopez EM, Walch K, Bales KL, Trainor BC. Sex-specific effects of stress on oxytocin neurons correspond with responses to intranasal oxytocin. Biol Psychiatry. 2016;80(5):406-14.

42. Duque-Wilckens N, Torres LY, Yokoyama S, Minie VA, Tran AM, Petkova SP, Hao R, Ramos-Maciel S, Rios RA, Jackson K, Flores-Ramirez FJ, Garcia-Carachure I, Pesavento PA, Iniguez SD, Grinevich V, et al. Extrahypothalamic oxytocin neurons drive stressinduced social vigilance and avoidance. Proc Natl Acad Sci. 2020;117(42):26406-13.

43. Laubu C, Dechaume-Moncharmont F-XX, Motreuil S, Schweitzer C. Mismatched partners that achieve postpairing behavioral similarity improve their reproductive success. Sci Adv. 2016;2(3):e1501013.

44. Arueti M, Perach-Barzilay N, Tsoory MM, Berger B, Getter N, Shamay-Tsoory SG. When Two Become One: The Role of Oxytocin in Interpersonal Coordination and Cooperation. J Cogn Neurosci. 2013;25(9):1418-27.

45. Trainor BC, Bird IM, Marler CA. Opposing hormonal mechanisms of aggression revealed 
through short-lived testosterone manipulations and multiple winning experiences. Horm Behav. 2004;45(2):115-21.

46. Oyegbile TO, Marler CA. Weak winner effect in a less aggressive mammal: Correlations with corticosterone but not testosterone. Physiol Behav. 2006;89(2):171-9.

47. Kalcounis-Rueppell MC, Metheny JD, Vonhof MJ. Production of ultrasonic vocalizations by Peromyscus mice in the wild. Front Zool. 2006;3(1):1-12.

48. Pultorak JD, Alger SJ, Loria SO, Johnson AM, Marler CA. Changes in Behavior and Ultrasonic Vocalizations During Pair Bonding and in Response to an Infidelity Challenge in Monogamous California Mice. Front Ecol Evol. 2018;6:125.

49. Gubernick DJ. Reproduction in the California Mouse, Peromyscus californicus. J Mammal. 1988;69(4):857-60.

50. Bales KL, Solomon M, Jacob S, Crawley JN, Silverman JL, Larke RH, Sahagun E, Puhger KR, Pride MC, Mendoza SP. Long-term exposure to intranasal oxytocin in a mouse autism model. Transl Psychiatry. 2014;4(11):480.

51. Leppanen J, Ng KW, Tchanturia K, Treasure J. Meta-analysis of the effects of intranasal oxytocin on interpretation and expression of emotions. Neurosci Biobehav Rev. 2017;78:125-44.

52. Guoynes CD, Simmons TC, Downing GM, Jacob S, Solomon M, Bales KL. Chronic Intranasal Oxytocin has Dose-dependent Effects on Central Oxytocin and Vasopressin Systems in Prairie Voles (Microtus ochrogaster). Neuroscience. 2018;369:292-302.

53. Smith AS, Korgan AC, Young WS. Oxytocin delivered nasally or intraperitoneally reaches the brain and plasma of normal and oxytocin knockout mice. Pharmacol Res. 2019;146:104324.

54. Duque-Wilckens N, Steinman MQ, Busnelli M, Chini B, Yokoyama S, Pham M, Laredo SA, Hao R, Perkeybile AM, Minie VA, Tan PB, Bales KL, Trainor BC. Oxytocin Receptors in the Anteromedial Bed Nucleus of the Stria Terminalis Promote StressInduced Social Avoidance in Female California Mice. Biol Psychiatry. 2018;83(3):20313.

55. Rieger NS, Spool JA, Riters L V., Marler CA. Unpublished data.

56. Pultorak JD, Matusinec KR, Miller ZK, Marler CA. Ultrasonic vocalization production and playback predicts intrapair and extrapair social behaviour in a monogamous mouse. Anim Behav. 2017;125:13-23.

57. Timonin ME, Kalcounis-Rueppell MC, Marler CA. Testosterone pulses at the nest site modify ultrasonic vocalization types in a monogamous and territorial mouse. Ethology. 2018;124(11):804-15.

58. Marler CA, Monari PK. Neuroendocrine control of vocalizations in rodents. In: Neuroendocrine Regulation of Animal Vocalization. Elsevier; 2021. p. 201-16.

59. Underhill V, Pandelis GG, Papuga J, Sabol AC, Rife A, Rubi T, Hoffman SMG, Dantzer B. Personality and behavioral syndromes in two Peromyscus species: presence, lack of state dependence, and lack of association with home range size. Behav Ecol Sociobiol. 
692

693

694

695

696

697

698

699

700

701

702

703

704

705

706

707

708

709

710

2021;75(1):1-16.

60. Careau V, Bininda-Emonds ORP, Thomas DW, Réale D, Humphries MM. Exploration strategies map along fast-slow metabolic and life-history continua in muroid rodents. Funct Ecol. 2009;23(1):150-6.

61. Wang L, Hou W, He Z, Yuan W, Yang J, Yang Y, Jia R, Zhu Z, Zhou Y, Tai F. Effects of chronic social defeat on social behaviors in adult female mandarin voles (Microtus mandarinus): Involvement of the oxytocin system in the nucleus accumbens. Prog NeuroPsychopharmacology Biol Psychiatry. 2018;82:278-88.

62. Marazziti D, Dell'Osso B, Baroni S, Mungai F, Catena M, Rucci P, Albanese F, Giannaccini G, Betti L, Fabbrini L, Italiani P, Del Debbio A, Lucacchini A, Dell'Osso L. A relationship between oxytocin and anxiety of romantic attachment. Clin Pract Epidemiol Ment Heal. 2006;2(1):1-6.

63. Laubu C, Louâpre P, Dechaume-Moncharmont FX. Pair-bonding influences affective state in a monogamous fish species. Proc R Soc B Biol Sci. 2019;286(1904).

64. Shaver PR, Hazan C. A biased overview of the study of love. J Soc Pers Relat. 1988;5(4):473-501.

65. von Zimmermann J, Vicary S, Sperling M, Orgs G, Richardson DC. The Choreography of Group Affiliation. Top Cogn Sci. 2018;10(1):80-94.

66. Ribble DO, Salvioni M. Social organization and nest co-occupancy in Peromyscus californicus, a monogamous rodent. Behav Ecol Sociobiol. 1990;26(1):9-15.

67. Bosch OJ, Young LJ. Oxytocin and social relationships: From attachment to bond disruption. Curr Top Behav Neurosci. 2018;35:97-117.

68. Webster MM, Ward AJW. Personality and social context. Biol Rev. 2011;86(4):759-73.

69. Réale D, Reader SM, Sol D, McDougall PT, Dingemanse NJ. Integrating animal temperament within ecology and evolution. Biol Rev. 2007;82(2):291-318.

70. Ostler J. Surviving Genocide: Native Nations and the United States from the American Revolution to Bleeding Kansas. Yale University Press; 2019. 